\title{
Evaluation of delayed timing of artificial insemination with sex-sorted sperm on pregnancy per artificial insemination in seasonal-calving, pasture-based lactating dairy cows
}

\author{
E. Drake, ${ }^{1,2}$ S. A. Holden, ${ }^{1} \odot$ V. Aublet, ${ }^{1}$ R. C. Doyle,,${ }^{1} \odot$ C. Millar, ${ }^{1}$ S. G. Moore, ${ }^{1} \odot$ C. Maicas,,${ }^{1,2} \odot$ F. Randi, ${ }^{3} \odot$ \\ A. R. Cromie, ${ }^{4}$ P. Lonergan, ${ }^{2}{ }^{-1}$ and S. T. Butler ${ }^{1 *}$ (i) \\ ${ }^{1}$ Teagasc, Animal and Grassland Research and Innovation Centre, Moorepark, Fermoy, Co. Cork, Ireland P61 C996 \\ ${ }^{2}$ School of Agriculture and Food Science, University College Dublin, Ireland D04 N2E5 \\ ${ }^{3}$ Ceva Santé Animale, Libourne, Bordeaux, France 33500 \\ ${ }^{4}$ Irish Cattle Breeding Federation, Highfield House, Shinagh, Bandon, Co. Cork, Ireland P72 X050
}

\section{ABSTRACT}

The objective was to use ovulation synchronization with timed artificial insemination (TAI) to evaluate the effect of timing of artificial insemination (AI) with frozen sex-sorted sperm on fertility performance in pasture-based compact calving herds. Ejaculates from 3 Holstein-Friesian bulls were split and processed to provide frozen sex-sorted sperm (SS) at $4 \times 10^{6}$ sperm per straw, and frozen conventional sperm at $15 \times 10^{6}$ sperm per straw (CONV). A modified Progesterone-Ovsynch protocol was used for estrous synchronization, with TAI occurring $16 \mathrm{~h}$ after the second $\mathrm{GnRH}$ injection for cows assigned to CONV, and either $16 \mathrm{~h}$ (SS-16) or 22 $\mathrm{h}$ (SS-22) for cows assigned to SS. Pregnancy diagnosis was conducted by transrectal ultrasound scanning of the uterus 35 to $40 \mathrm{~d}$ after TAI $(\mathrm{n}=2,175$ records available for analysis). Generalized linear mixed models were used to examine the effects of treatment on pregnancy per artificial insemination $(\mathrm{P} / \mathrm{AI})$. Fixed effects included treatment $(\mathrm{n}=3)$, bull $(\mathrm{n}=3)$, treatment by bull interaction, parity $(\mathrm{n}=4)$, days-in-milk category $(\mathrm{n}=3)$, and treatment by days-in-milk category, with herd $(\mathrm{n}=24)$ included as a random effect. Pregnancy per AI was greater for CONV compared with both SS-16 and SS-22 (61.1\%, $49.0 \%$, and $51.3 \%$, respectively), and the SS treatments did not differ from each other (relative P/AI for SS-16 and SS-22 vs. CONV were $80.2 \%$ and $84.0 \%$, respectively). There were significant bull and treatment by bull interaction effects. Additional analysis was undertaken using a model that included herd as a fixed effect. This analysis identified marked herd-to-herd variation (within-herd relative $\mathrm{P} / \mathrm{AI}$ for the combined SS treatments vs. CONV ranged from

Received May 5, 2020

Accepted August 3, 2020.

*Corresponding author: stephen.butler@teagasc.ie
48-121\%). The tertile of herds with the best performance achieved a mean relative $\mathrm{P} / \mathrm{AI}$ of $100 \%$ (range $=$ 91-121\%), indicating that $\mathrm{P} / \mathrm{AI}$ equivalent to CONV is achievable with SS. Conversely, the tertile of herds with the poorest performance achieved a mean relative $\mathrm{P} / \mathrm{AI}$ of $67 \%$ (range $=48-77 \%$ ). We found that SS resulted in poorer overall $\mathrm{P} / \mathrm{AI}$ compared with $\mathrm{CONV}$ sperm regardless of timing of AI. Marked variation existed between herds; however, one-third of herds achieved $\mathrm{P} / \mathrm{AI}$ results equal to CONV. Identification of factors responsible for the large herd-to-herd variation in $\mathrm{P} / \mathrm{AI}$ with SS, and development of strategies to reduce this variation, warrant further research.

Key words: sex-sorted sperm, synchronization, fixed time artificial insemination, seasonal calving

\section{INTRODUCTION}

Seasonal-calving pasture-based systems of milk production focus on maximizing the use of grazed grass in the diet (Dillon et al., 1995; Shalloo et al., 2004). The target is for $90 \%$ of the herd to calve within 6 wk after the planned start of calving, with every $1 \%$ increase in 6 -wk calving rate resulting in a corresponding increase in profitability of $€ 822$ for a 100 -cow herd (Shalloo et al., 2014). When conventional (CONV) sperm is used, approximately $50 \%$ of the calves born will be male and of low economic value, raising potential animal welfare issues (Holden and Butler, 2018).

The potential benefits of sex-sorted sperm (SS) have been well documented and include an estimated $20 \%$ reduction in the occurrence of dystocia, improved biosecurity arising from on-farm breeding of replacement heifers, and the facilitation of crossbreeding to yield predominantly female calves (Seidel, 2003; Weigel, 2004). Furthermore, targeted usage of SS to generate replacement heifers at the start of the breeding season and use of beef sires for all other inseminations can increase the value of beef output from the dairy herd 
(Butler et al., 2014). Despite these potential benefits, the uptake of SS remains low in pasture-based systems of milk production that are reliant on excellent fertility and a concentrated period of calving. This is primarily due to concerns regarding reduced fertility of sex-sorted sperm and the associated economic losses.

Fluorescence-activated cell sorting via flow cytometry is the most widely used process for sex-sorting sperm based on differences in DNA content (Garner et al., 2013). In cattle, X-chromosome-bearing sperm contain approximately $3.8 \%$ more DNA than Y-chromosomebearing sperm. This method typically results in a $\sim 90 \%$ sex-bias semen straw (Johnson, 1995). Sex-sorted sperm has been reported to have a shorter fertile lifespan after the sorting process (Vishwanath and Moreno, 2018). Reasons for this reduced longevity are multifactorial, including nuclear staining, pressure, exposure to lasers, physical stress, extended processing time, and dilution (Maxwell and Johnson, 1997; Maxwell et al., 1998; Maxwell et al., 2004; Suh et al., 2005; Schenk et al., 2009).

Bioeconomic modeling studies have indicated that SS usage in both heifers and cows in expanding herds can increase farm profitability despite reduced fertility (Hutchinson et al., 2013a,b). A recent field trial evaluated the fertility of frozen SS $\left(4 \times 10^{6}\right.$ per straw $)$ compared with frozen CONV $\left(15 \times 10^{6}\right.$ per straw $)$ under seasonal pasture-based conditions. Overall, a relative pregnancy per artificial insemination $(\mathbf{P} / \mathbf{A I})$ of $76 \%$ (SS relative to $\mathrm{CONV}$ ) was reported, which was apparently better for bulls that were resident at the sorting laboratory $(84 \%)$ compared with those that had ejaculates transported for 6 to $7 \mathrm{~h}$ to the sorting laboratory (70\%; Maicas et al., 2020). That study also identified marked herd-to-herd variation, with $33 \%$ of herds achieving a relative $\mathrm{P} / \mathrm{AI}$ of $\geq 90 \%$. Based on this variation, it was hypothesized that herd management (including timing of AI) may have played a role in variable P/AI results between herds (Maicas et al., 2020). Previous studies that used timed AI (TAI) protocols (without a final injection of $\mathrm{GnRH}$ to induce ovulation; Sales et al., 2011; Thomas et al., 2014), or that evaluated time of AI relative to an increase in activity (Bombardelli et al., 2016), have suggested that delaying the timing of AI to be closer to the time of ovulation has a favorable effect on $\mathrm{P} / \mathrm{AI}$ achieved with SS. This presumably reflects the presence of a larger population of viable sperm in the female reproductive tract at the time of ovulation. Ovulation synchronization and TAI have been extensively evaluated in seasonal-calving systems, and have been shown to shorten the interval from the start of the breeding period to pregnancy establishment compared with nonsynchronized animals (Herlihy et al., 2011; Randi et al., 2018). The objective of this study was to evaluate the effect of timing of $\mathrm{AI}$ on $\mathrm{P} /$ AI for SS in a pasture-based, compact calving production system. We tested the hypothesis that delaying timing of AI with SS would increase P/AI.

\section{MATERIALS AND METHODS}

\section{Semen Collection}

This study was carried out in spring of 2019. Three Holstein-Friesian bulls were selected by the collaborating Irish AI companies to produce SS sperm straws for commercial sale, and these bulls were transported to a semen collection center in close proximity to a sperm sorting laboratory (Cogent Breeding Ltd., Chester, United Kingdom). Ejaculates were collected by experienced operators using an artificial vagina and immediately delivered to the sex-sorting laboratory. Semen was processed in the laboratory and subjected to quality control and testing as described in detail by Maicas et al. (2019). To produce straws for the field trial, each ejaculate was split into 2 aliquots and either processed for CONV straws (not SS) with a concentration of 15 $\times 10^{6}$ sperm per straw, or SS $(90 \%$ X-chromosome biased), using the SexedULTRA Genesis III system as described by Vishwanath and Moreno (2018), with a concentration of $4 \times 10^{6}$ total sperm per straw.

\section{Participating Herds}

Herds were recruited with the cooperation of the Irish Cattle Breeding Federation (ICBF; Bandon, Co. Cork, Ireland), which maintains the national database for cattle data collection in Ireland, in conjunction with participating Irish AI companies (Dovea Genetics, Thurles, Co. Tipperary; Munster Bovine, Mallow, Co. Cork; and Progressive Genetics, Enfield, Co. Meath). Herds were required to have a mating start date in mid to late April, with 100 cows meeting eligibility criteria based on parity (1-4 inclusive) and DIM ( $\geq 50$ DIM on the day of AI). Herds meeting these criteria $(\mathrm{n}=24)$ were enrolled in the study. Enrolled cows were classified as Holstein-Friesian (82.0\%), Jersey (10.7\%), BritishFriesian (5.3\%), Norwegian Red (1.5\%), or Ayrshire (0.5\%). Each herd received 100 straws (approximately two-thirds SS and one-third CONV), and the proportion of CONV and SS straws from each bull was identical for each herd.

\section{Prebreeding Ultrasound Scanning, Synchronization, and Experimental Treatments}

Transrectal ultrasonography to assess uterine health and ovarian status was performed on eligible cows by 
experienced veterinary practitioners. The number of corpora lutea (CL) was recorded, and a 4-point ultrasound reproductive tract score (URTS) scale adapted from Mee et al. (2009) was used to assess uterine health status. Only cows with a URTS $\leq 2$ were enrolled in the study.

A modified 10-d Progesterone-Ovsynch protocol adapted from Herlihy et al. (2011) was used (Figure 1). On $\mathrm{d}-10$ relative to the farm mating start date, a 2-mL i.m. injection of GnRH analog (Ovarelin, 100 $\mu \mathrm{g}$ of gonadorelin diacetate tetrahydrate; Ceva Santé Animale, Libourne, France) was administered, and a progesterone-releasing intravaginal device (PRID; Ceva Santé Animale) was inserted. On d -3 , a $5-\mathrm{mL}$ i.m. injection of $\mathrm{PGF}_{2 \alpha}$ (Enzaprost, $25 \mathrm{mg}$ of dinoprost trometamol; Ceva Santé Animale) was administered. On $\mathrm{d}-2$, a second 5-mL i.m. of $\mathrm{PGF}_{2 \alpha}$ was administered and the PRID was removed. On $\mathrm{d}-1$ ( $32 \mathrm{~h}$ after PRID removal) a second i.m. injection of GnRH was administered.

The experiment was a completely randomized block design. Within each herd, synchronized cows were stratified based on parity and DIM, and randomly assigned to 1 of 3 treatments: (1) TAI $16 \mathrm{~h}$ after the second GnRH injection with a CONV straw (CONV), (2) TAI $16 \mathrm{~h}$ after the second GnRH injection with a SS straw (SS-16), or (3) TAI $22 \mathrm{~h}$ after the second GnRH injection with a SS straw (SS-22). One of 3 different oil-based tail paint colors (Tell Tail; FIL, Mount Maunganui, New Zealand) that corresponded to the cow treatment was used to make a visible strip across the middle of the back of every cow on the day of synchronization protocol initiation. This served 2 purposes: (1) aid identification of the specific cows within the herd that were enrolled in the study and would require hormonal interventions and (2) aid identification of cows that required AI at 16 (and whether SS or CONV semen) or $22 \mathrm{~h}$ (SS only) after the final $\mathrm{GnRH}$ injection. The initiation of the protocol on $\mathrm{d}$ -10 was implemented by a veterinary practitioner, and the remaining interventions were undertaken by the herdowner or farm staff. On the day of protocol initiation, all herdowners were given their farm-specific timetable of the remaining interventions and the exact

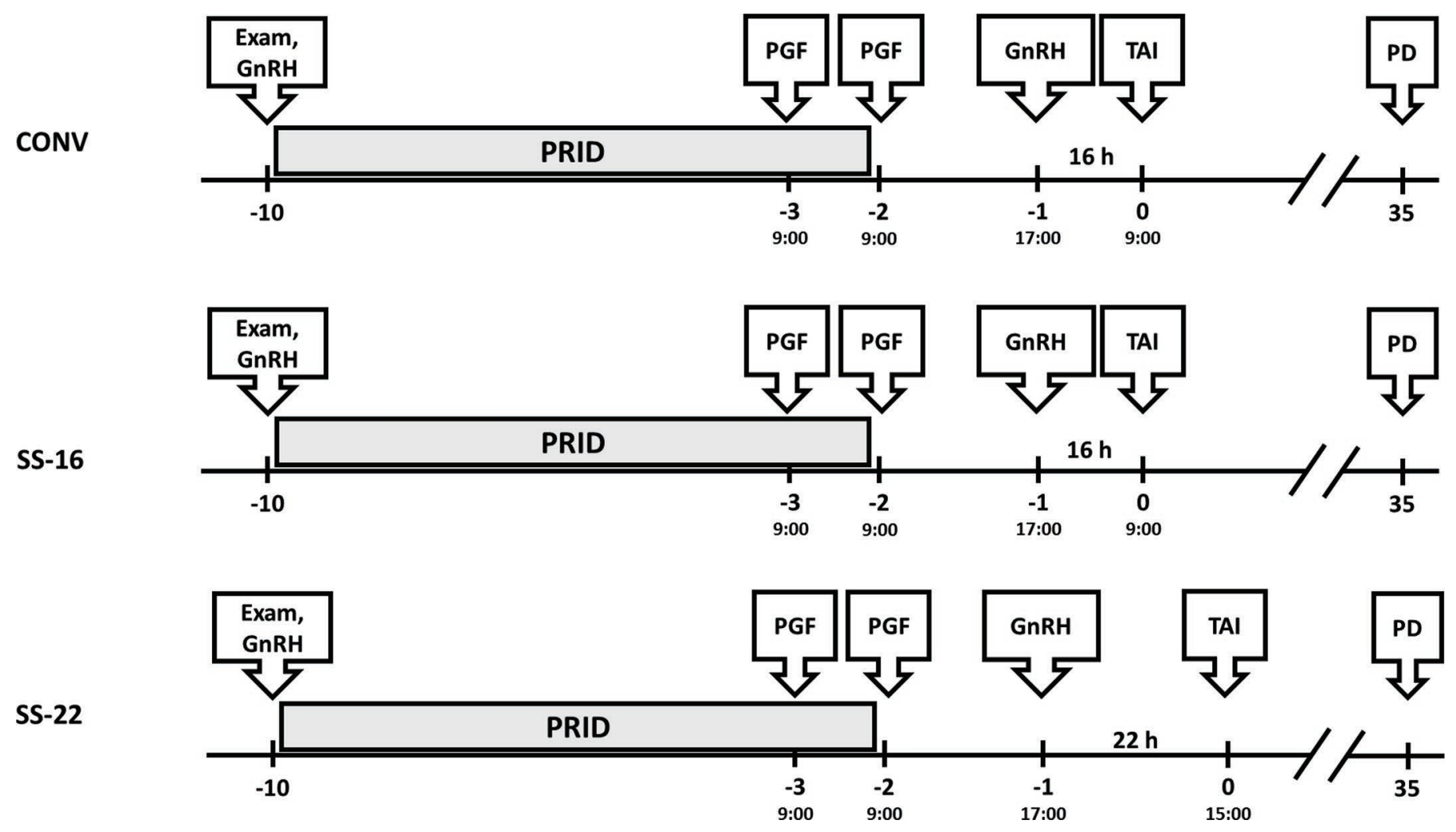

Figure 1. Schematic diagram summarizing the synchronization protocol used and timing of AI. On d -10 (i.e., $10 \mathrm{~d}$ before AI date), cows were scanned to verify suitability, an injection of GnRH was administered, and a progesterone-releasing intravaginal device (PRID) was inserted On $\mathrm{d}-3$, an injection of $\mathrm{PGF}_{2 \alpha}$ (PGF) was administered. On d -2 a second injection of PGF was administered and the PRID was removed at $0900 \mathrm{~h}$. On d -1, an injection of GnRH was administered at $1700 \mathrm{~h}$. On d 0, timed AI (TAI) was conducted at either $0900 \mathrm{~h}(16 \mathrm{~h}$ after second GnRH: CONV and SS-16) or $1500 \mathrm{~h}$ (22 h after second GnRH; SS-22). At 35 to $40 \mathrm{~d}$ after TAI, pregnancy diagnosis (PD) was conducted using transrectal ultrasound. 
supply of required hormones, syringes, and needles. In addition, each herdowner received communication from a member of the research team the day before every intervention with a reminder of the specific intervention needed and the time that the intervention should be undertaken. Finally, all herdowners were provided with print-out sheets of the list of cows in each treatment, indicating which cows needed to be made available for $\mathrm{AI}$ at 16 and $22 \mathrm{~h}$ after GnRH. This sheet also ranked the bulls in order of suitability to breed each cow (and minimize inbreeding) based on sire mating advice software developed by the ICBF.

All inseminations were recorded on a hand-held device by a professional AI technician, and data were subsequently uploaded via an application program interface link to the ICBF database (www.icbf.com). Upon completion of all inseminations, data including cow identification number, treatment straw, bull code, cow parity, calving date, and breed were extracted from the ICBF database.

Pregnancy was diagnosed by transrectal ultrasound scanning of the uterus 35 to $40 \mathrm{~d}$ after AI. All pregnancy diagnosis results were compiled into a single database and merged with insemination and cow information data. Data from a total of 2,175 cows were available for analysis. The average number of cows per herd was 91 (range 62-100). The number of inseminations per bull ranged from 579 to 892 .

\section{Data Handling and Statistical Analysis}

Cows were removed from the data set for the following reasons: lost PRID $(\mathrm{n}=30)$, PRID removal at time of AI $(\mathrm{n}=1)$, inseminated with nontrial bull $(\mathrm{n}=23)$, missing record of insemination event $(\mathrm{n}=21)$, incorrect sperm treatment recorded $(\mathrm{n}=13)$, ovarian cyst $(\mathrm{n}=$ 5 ), uterine disease (i.e., URTS $\geq 3 ; \mathrm{n}=1$ ), ovarian tumor $(\mathrm{n}=1)$, and lameness $(\mathrm{n}=1)$. The variable DIM was divided into 3 categories: 50 to 70,71 to 79 , and $\geq 80$ (each DIM category had an approximately equal numbers of cows). Parity was divided into 4 categories: 1, 2, 3, and 4 (Table 1). The number of CL visible on the ovary on the day of initiation of synchronization was categorized as 0 or $\geq 1$. A generalized linear mixed model (PROC GLIMMIX, SAS 9.4, SAS Institute Inc., Cary, NC) was used to evaluate the effect of treatment on P/AI. The experimental unit was considered to be cow, and fixed effects in the model included treatment $(\mathrm{n}=3)$, bull $(\mathrm{n}=3)$, treatment by bull interaction, parity $(\mathrm{n}=4)$, DIM category $(\mathrm{n}=3)$, and treatment by DIM category. Herd $(\mathrm{n}=24)$ was included as a random effect.

Herd mean P/AI for each treatment was calculated, and these data were used to create a box-and-whiskers plot to visualize the between-herd variation in $\mathrm{P} / \mathrm{AI}$ for each treatment. As the mean $\mathrm{P} / \mathrm{AI}$ was similar and the between-herd variation for P/AI was large for both SS-16 and SS-22, these 2 SS treatments were combined to form a single SS treatment. Generalized linear mixed models were then used to evaluate herd and AI technician effects in separate models. Fixed effects in the models included treatment $(\mathrm{n}=3)$, bull $(\mathrm{n}=3)$, treatment by bull interaction, herd (or AI technician), and treatment by herd (or AI technician) interaction. The SLICE statement was used to perform a partitioned analysis of the least squares means for the treatment by herd (or AI technician) interaction.

The relative $\mathrm{P} / \mathrm{AI}$ was calculated as $[(\mathrm{SS} \mathrm{P} / \mathrm{AI} \div$ CONV P $/ \mathrm{AI}) \times 100]$. A relative $\mathrm{P} / \mathrm{AI}$ of $<100 \%, 100 \%$, or $>100 \%$ indicated that the $\mathrm{P} / \mathrm{AI}$ achieved by SS was less than, equal to, or greater than the P/AI for CONV, respectively.

\section{RESULTS}

\section{Factors Affecting P/AI}

Treatment had an effect on $\mathrm{P} / \mathrm{AI}(P<0.001$; Figure 2 ). Both SS-16 and SS-22 resulted in lesser P/AI compared with CONV, and did not differ from each other. The relative P/AI for SS-16 and SS-22 was $80.2 \%$ and $84.0 \%$, respectively. The presence or absence of a CL, the URTS score at the start of the synchronization protocol, parity, and DIM category did not affect $\mathrm{P} / \mathrm{AI}$

Table 1. Characteristics of cows enrolled on the trial

\begin{tabular}{lrc}
\hline Variable & $\mathrm{n}$ & $\%$ \\
\hline Parity $^{1}$ & & \\
1 & 843 & 38.8 \\
2 & 556 & 25.6 \\
3 & 423 & 19.5 \\
4 & 353 & 16.2 \\
DIM $^{2}$ & & \\
$50-70$ & 707 & 32.5 \\
$71-79$ & 743 & 34.2 \\
$\geq 80$ & 725 & 33.3 \\
CL $^{3}$ & & \\
0 & 328 & 15.6 \\
1 & 1,606 & 76.6 \\
2 & 161 & 7.7 \\
3 & 3 & 0.1 \\
URTS $^{4}$ & & 78.0 \\
1 & 1,635 & 22.0 \\
2 & 461 & \\
\hline
\end{tabular}

${ }^{1}$ Parity = lactation number.

${ }^{2}$ DIM on the day of timed AI.

${ }^{3} \mathrm{CL}=$ number of corpora lutea present on the day of synchronization protocol initiation.

${ }^{4}$ URTS $=$ uterine ultrasound reproductive tract score on the day of synchronization protocol initiation. 


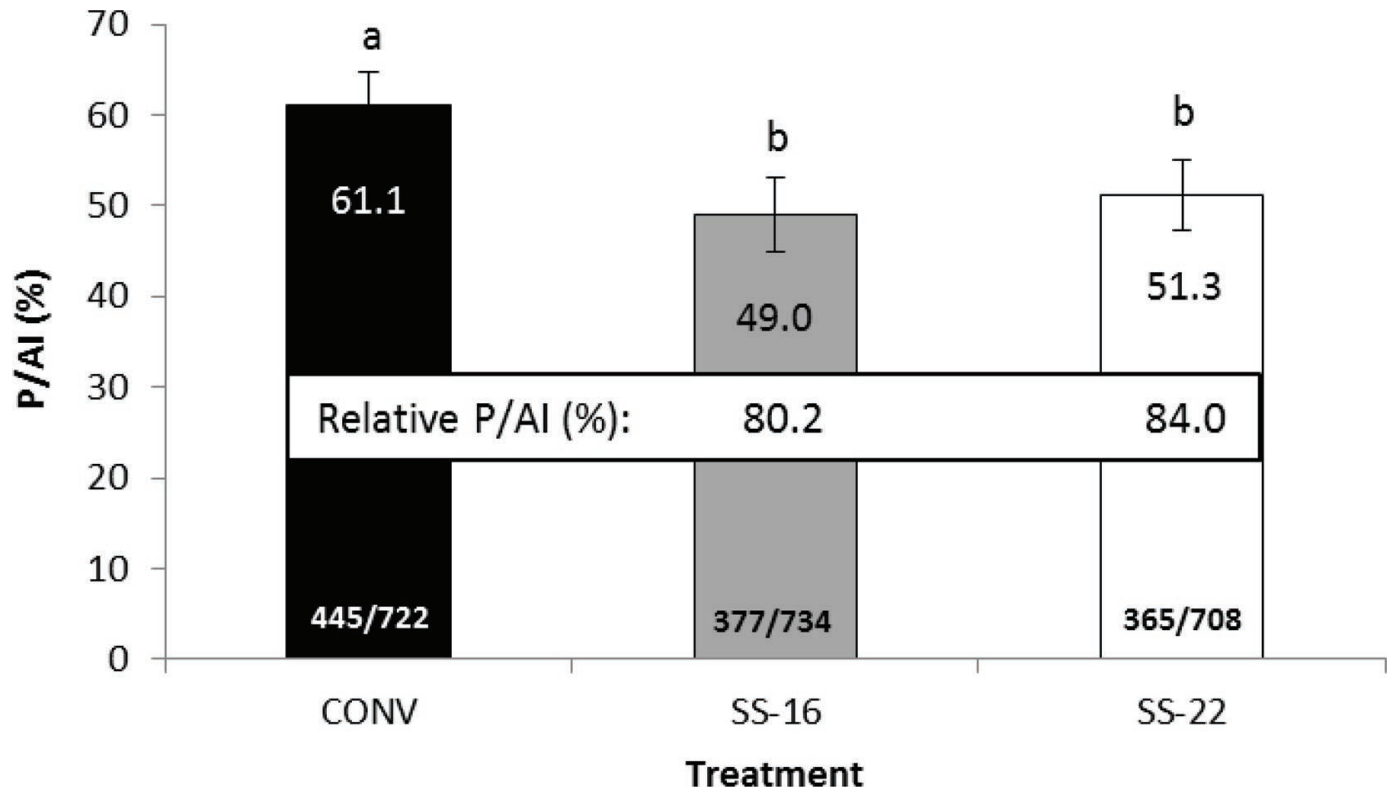

Figure 2. The effect of sperm treatment and timing of AI on pregnancy per AI (P/AI) in lactating dairy cows. There was a treatment effect on $\mathrm{P} / \mathrm{AI}(P<0.001)$. The values in the black box indicate the relative $\mathrm{P} / \mathrm{AI}$ of the sex-sorted (SS) treatments compared with conventional $(\mathrm{CONV})$. Treatments with different letters $(\mathrm{a}, \mathrm{b})$ differ $P<0.001$. Error bars denote lower and upper limits of $95 \%$ confidence intervals. The numbers of pregnant and total cows for each treatment are indicated at the base of each bar. CONV = timed AI $16 \mathrm{~h}$ after the second GnRH injection with a conventional semen straw; SS-16 = timed AI 16 h after the second GnRH injection with a sexed semen straw; SS-22 = timed AI $22 \mathrm{~h}$ after the second GnRH injection with a SS straw.

(all $P>0.1$ ). The herd-to-herd variation in $\mathrm{P} / \mathrm{AI}$ was considerably greater in both SS treatments compared with the CONV treatment (Figure 3).

Bull had an effect on $\mathrm{P} / \mathrm{AI}(P=0.047)$. Across all treatments, the $\mathrm{P} / \mathrm{AI}$ for bulls 1,2 , and 3 were $55.2 \%$, $49.7 \%$, and $56.6 \%$ respectively. A bull by treatment interaction $(P<0.05)$ was also detected (Figure 4$)$. Both SS treatments resulted in lesser $(P<0.05) \mathrm{P} / \mathrm{AI}$ compared with CONV for bull 1. For bull 2, SS-16 resulted in lesser $(P<0.05) \mathrm{P} / \mathrm{AI}$ compared with CONV and SS-22, whereas P/AI for SS-22 did not differ from CONV. There was no difference between treatments for bull 3 .

\section{Herd Variation in Relative P/AI}

There was considerable variation in $\mathrm{P} / \mathrm{AI}$ between herds. When the $2 \mathrm{SS}$ treatments were combined, a treatment effect on $\mathrm{P} / \mathrm{AI}$ was also detected (61.1 vs. $50.9 \% ; P<0.001)$. Herds were ranked in order of decreasing relative $\mathrm{P} / \mathrm{AI}$ (Figure 5). The mean relative $\mathrm{P} /$ AI was $83.3 \%$, with a range from 48 to $121 \%$ between herds. The best tertile, intermediate tertile, and poorest tertile of herds ( $\mathrm{n}=8$ herds per tertile) achieved mean (and range) relative P/AI of $100 \%$ (91-121\%), $84 \%(78-89 \%)$, and $67 \%(48-77 \%)$, respectively. Of note, in the tertile of herds with the poorest relative $\mathrm{P} / \mathrm{AI}$, the $\mathrm{P} / \mathrm{AI}$ achieved with $\mathrm{CONV}$ was greater than both the intermediate tertile and best tertile $(66.0 \%$, $59.0 \%$, and $59.6 \%$, respectively).

\section{Technician Variation and P/AI}

Eighteen technicians were involved in the study. Technicians were ranked based on the relative $\mathrm{P} / \mathrm{AI}$ calculated using the combined SS treatments (Figure 6). Technicians 1 and 2 were assigned to 2 herds and 4 herds, respectively, while all other technicians were assigned to a single herd. There was no effect of technician on $\mathrm{P} / \mathrm{AI}$ with $\mathrm{CONV}(P=0.99)$, but there was an effect of technician on $\mathrm{P} / \mathrm{AI}$ with $\mathrm{SS}(P=0.052)$. The $\mathrm{P} / \mathrm{AI}$ for SS achieved by technicians 16,17 , and 18 was poorer $(P<0.05)$ than that achieved by technicians 1 , 2 , and 3 , but $\mathrm{P} / \mathrm{AI}$ for $\mathrm{CONV}$ did not differ (Figure 6 ).

\section{DISCUSSION}

This study used an ovulation synchronization protocol to evaluate the effect of timing of AI with SS on $\mathrm{P} / \mathrm{AI}$. The main findings were that $\mathrm{P} / \mathrm{AI}$ did not differ between SS treatments (SS-16 and SS-22), and both SS treatments were poorer than CONV. Similar to previous studies, bull and bull by treatment interaction effects were detected. Of particular note, herd-to-herd variation in $\mathrm{P} / \mathrm{AI}$ was markedly greater for both $\mathrm{SS}$ treatments compared with the CONV treatment. 




Figure 3. Box and whisker plot indicating the interquartile ranges in herd mean pregnancy per AI (P/AI) for each treatment. The ends of the whiskers represent the maximum and minimum $\mathrm{P} / \mathrm{AI}$ for an individual herd. The upper and lower quartiles make up the boundaries of the box. The height of the box represents the interquartile range, and the median is indicated by the horizontal line within the box. The arithmetic mean P/AI for each treatment is indicated by the diamond. For SS-22, one herd was identified as an outlier (open circle). Greater variation is evident for the 2 sex-sorted (SS) treatments compared with the conventional (CONV) treatment. CONV $=$ timed AI $16 \mathrm{~h}$ after the second GnRH injection with a conventional semen straw; SS-16 = timed AI 16 h after the second GnRH injection with a sexed semen straw; SS-22 = timed AI $22 \mathrm{~h}$ after the second GnRH injection with a SS straw.

Overall, P/AI for both SS and CONV treatments were comparable with previous studies, where CONV was reported to have a better field fertility performance compared with SS (Schenk et al., 2009; Karakaya et al., 2014). Maicas et al. (2020) recently reported P/AI results in lactating dairy cows following insemination with CONV or SS (Sexed ULTRA 4M) after detected estrus (59.9\% and $45.5 \%$, respectively). No differences were observed between the 2 SS treatments in the current study, failing to support the original hypothesis that delaying timing of $\mathrm{AI}$ would benefit $\mathrm{P} / \mathrm{AI}$ with SS. This agrees with a recent report by Chebel and Cunha (2020), who treated heifers with a 5-d CoSynch protocol and used activity monitors to detect onset of estrus during a 72 -h period after $\mathrm{PGF}_{2 \alpha}$ administration. Heifers that exhibited estrus were assigned to receive AI either immediately after onset of estrus (CONV or SSEarly) or $12 \mathrm{~h}$ after onset of estrus (SSLate). Heifers that did not exhibit estrus by $72 \mathrm{~h}$ after $\mathrm{PGF}_{2 \alpha}$ were administered $\mathrm{GnRH}$ and assigned to receive AI either immediately after GnRH (CONV or SSEarly) or $12 \mathrm{~h}$ after GnRH (SSLate). The authors reported that P/AI was not different between heifers that received SSEarly or SSLate, and both had poorer P/AI compared with CONV. In a study using the Double Ovsynch protocol with primiparous dairy cows, Lauber et al. (2020) reported that delaying timing of AI with SS from 16 to $24 \mathrm{~h}$ after the final GnRH reduced $\mathrm{P} / \mathrm{AI}$ in primiparous dairy cows. However, in contrast to the current study, Lauber et al. (2020) fixed the time of AI for all cows (48 $\mathrm{h}$ after final $\mathrm{PGF}_{2 \alpha}$ ) and varied the interval from the last $\mathrm{PGF}_{2 \alpha}$ to $\mathrm{GnRH} 2$ (24 vs. $32 \mathrm{~h}$ ), and thereby time from GnRH2 to TAI ( 24 vs. $16 \mathrm{~h}$ ). Thus, timing of AI was likely confounded with differences in preovulatory follicle size, stage of follicle development, and circulating progesterone and estradiol concentrations when GnRH2 was administered to induce ovulation. Nevertheless, the collective observations from both the current study and the available literature indicate that 16 to $22 \mathrm{~h}$ after the second GnRH injection likely encompasses the optimum window for timing of AI with SS in lactating dairy cows.

Several studies have used synchrony protocols that did not use GnRH before AI to induce ovulation. Sales 
et al. (2011) observed greater P/AI with SS when TAI was performed between 0 to $12 \mathrm{~h}$ before ovulation compared with 12 to $14 \mathrm{~h}$ before ovulation. This is consistent with the observations in the current study, as timing of AI for both SS-16 and SS-22 should have occurred between 0 and $12 \mathrm{~h}$ before ovulation (expected time of ovulation after final $\mathrm{GnRH}$ is approximately 28 h later; Herlihy et al., 2012). Schenk et al. (2009) inseminated Angus heifers with SS at either 55 to 56 $\mathrm{h}$ or 67 to $68 \mathrm{~h}$ after progesterone device-removal and $\mathrm{PGF}_{2 \alpha}$ administration, and reported that delaying timing of AI improved P/AI with SS (49\% with delayed TAI vs. $34 \%$ with standard TAI). Conversely, administering GnRH at the time of AI, Hall et al. (2017) reported no difference in $\mathrm{P} / \mathrm{AI}$ in beef cows receiving TAI with SS at 80 versus $72 \mathrm{~h}$ after the first $\mathrm{PGF}_{2 \alpha}$ injection in a CoSynch TAI protocol.

In agreement with previous studies, bull had a significant effect on $\mathrm{P} / \mathrm{AI}$ in the current study (Frijters et al., 2009; Sá Filho et al., 2013; Hall et al., 2017; Thomas et al., 2019; Maicas et al., 2019). Ejaculates from each bull on the trial were subjected to industry-standard spermquality evaluation assessments including concentration, morphology, and motility assessments. Unsatisfactory field fertility with SS is still a barrier to widespread commercial utilization, particularly in compact calving systems. Holden et al. (2017) suggested that a suite of custom in vitro assessment techniques for different

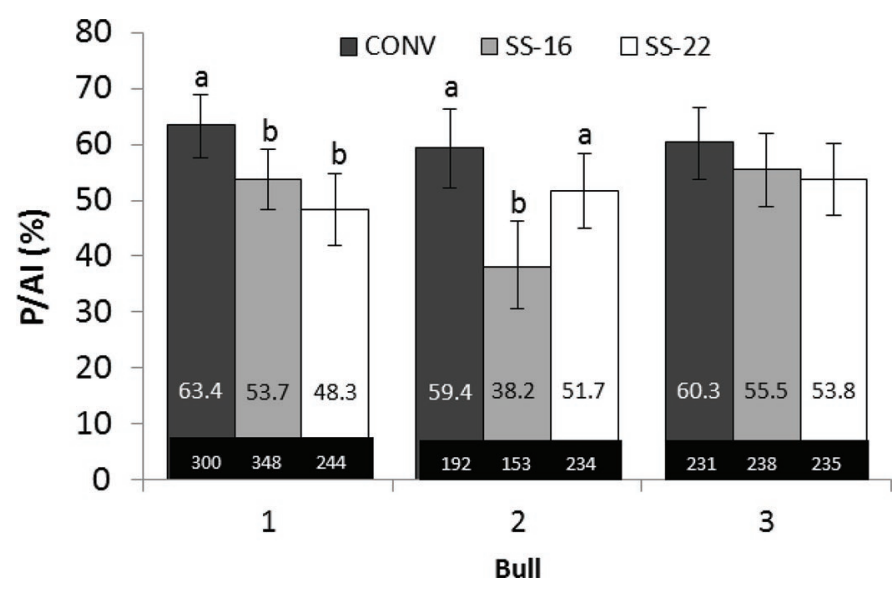

Figure 4. Illustration of the interaction between bull and treatment on pregnancy per AI $(\mathrm{P} / \mathrm{AI})$. There was a treatment by bull interaction $(P<0.001)$. The upper value within each bar is the model adjusted mean $\mathrm{P} / \mathrm{AI}$ for each treatment and bull combination. The lower value within each bar indicates the number of inseminations for each treatment and bull combination. Within each bull, treatment means with different letters $(\mathrm{a}, \mathrm{b})$ differ $(P<0.05)$. Error bars denote lower and upper limits of the $95 \%$ confidence interval. CONV $=$ conventional treatment; $\mathrm{SS}=$ sex-sorted treatment. $\mathrm{CONV}=$ timed $\mathrm{AI} 16$ $\mathrm{h}$ after the second $\mathrm{GnRH}$ injection with a conventional semen straw; SS-16 = timed AI $16 \mathrm{~h}$ after the second $\mathrm{GnRH}$ injection with a sexed semen straw; SS-22 = timed AI $22 \mathrm{~h}$ after the second GnRH injection with a SS straw. sperm treatments (CONV vs. SS), rather than general quality assessments, may help to identify and eliminate bulls whose sperm characteristics are not suited to the sex-sorting process. Split ejaculates (CONV and SS straws originated from same ejaculate) were used in the current study to eliminate possible effects of ejaculate variation on $\mathrm{P} / \mathrm{AI}$, similar to previous studies (Xu et al., 2018; Bo et al., 2019; Maicas et al., 2019, 2020).

A bull by treatment interaction on $\mathrm{P} / \mathrm{AI}$ was observed in the current study. This occurred because bull 2 had an improvement in $\mathrm{P} / \mathrm{AI}$ when SS was used at the later time (SS-22) compared with the normal time (SS-16), which provided partial support for the hypothesis that delaying timing of AI closer to the time of ovulation would improve $\mathrm{P} / \mathrm{AI}$ for SS. This finding perhaps indicated that the timing of AI with SS is more critical for some bulls than for others. Further research is needed to identify tests that accurately identify individual bulls that are more sensitive to timing of AI with SS.

The variation between herds in mean $\mathrm{P} / \mathrm{AI}$ was small for CONV, but large for both SS treatments. All herds achieved acceptable P/AI with CONV, where the target in seasonal-calving herds is $\geq 60 \%$ (Burke at al., 2007; Butler, 2014). Of note, in the third of herds with the poorest relative $\mathrm{P} / \mathrm{AI}, \mathrm{P} / \mathrm{AI}$ with $\mathrm{CONV}$ was better than both the intermediate and best third of herds. This indicated that the cows in these herds were fertile, the synchronization protocol was correctly implemented, a high fertility ovulation event was induced, and AI was conducted at the appropriate time. In the third of the herds with the best relative $\mathrm{P} / \mathrm{AI}$, the $\mathrm{P} / \mathrm{AI}$ results achieved with SS were similar to CONV. This indicated that neither the SS itself nor the times chosen for TAI were the primary causes of compromised fertility performance in the herds that had poor P/ AI with SS. Accuracy of heat detection and timing of AI have been highlighted previously as possible reasons for herd-to-herd variability in P/AI with SS (Arruda et al. 2012; Thomas et al. 2014). In the current study, however, heat detection was eliminated as a source of variation due to the implementation of a synchronization protocol to control timing of ovulation, thereby allowing TAI. Herd-to-herd variation was also observed by Maicas et al. (2019), whereby approximately $33 \%$ of enrolled herds achieved a relative $\mathrm{P} / \mathrm{AI}$ of $\geq 90 \%$, with the majority of that subset of herds achieving a relative $\mathrm{P} / \mathrm{AI}$ of $\geq 100 \%$. Herd management factors may account for some of this variation, with farms achieving excellent P/AI results with SS when providing conditions suited to SS usage, but the exact contributory factors remain undefined. In the current study, within each herd, treatments were balanced for parity and DIM, and cows within each herd were exposed to the same nutrition and herd management conditions. The 


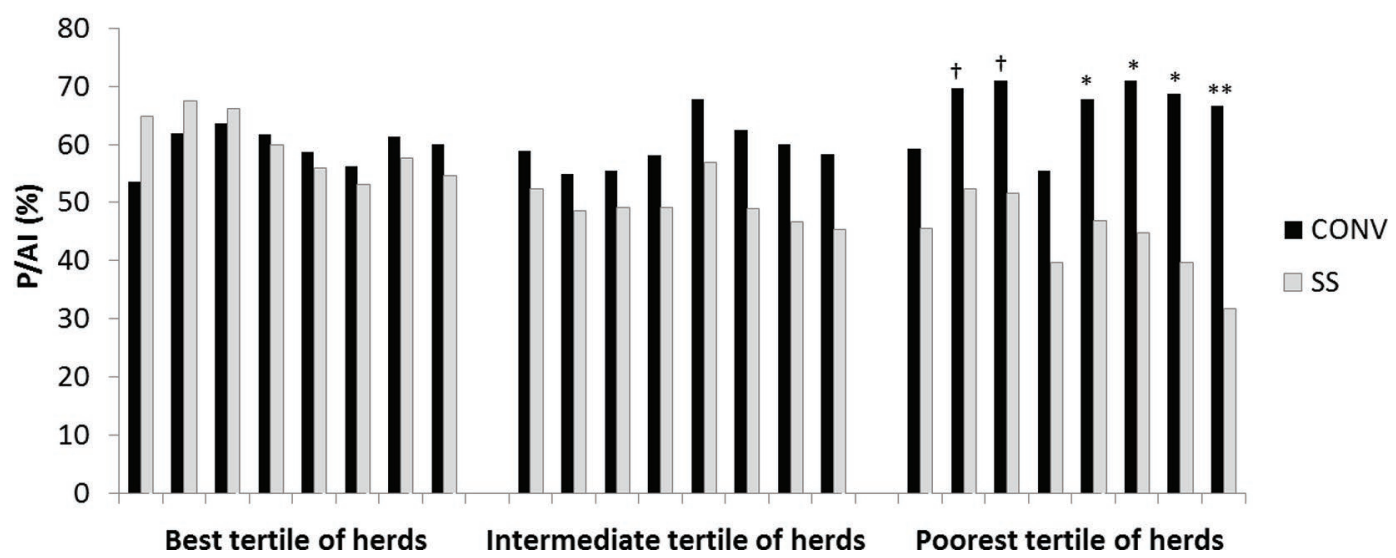

Figure 5. Mean pregnancy per AI (P/AI) for conventional (CONV) and sex-sorted (SS; SS-16 and SS-22 combined) within each study herd, ranked based on relative $\mathrm{P} / \mathrm{AI}[\mathrm{SS} \mathrm{P} / \mathrm{AI} \div \mathrm{CONV} \mathrm{P} / \mathrm{AI}) \times 100]$. Herds were divided into tertiles (best, intermediate, and poorest based on relative $\mathrm{P} / \mathrm{AI}$ ). The mean (and range) relative (Rel.) $\mathrm{P} / \mathrm{AI}$ for each tertile is indicated in the black boxes at the top of the figure. The type 3 test of fixed effects for treatment by herd interaction was not significant $(P=0.66)$. Partitioning the least squares means for the treatment by herd interaction using the SLICE statement indicated a significant effect for SS $(P=0.03)$ but not $\operatorname{CONV}(P=0.99)$. †P<0.1; ${ }^{*} P<0.05 ; * * P<$ 0.01. $\mathrm{CONV}=$ timed AI $16 \mathrm{~h}$ after the second GnRH injection with a conventional semen straw; SS-16 = timed AI $16 \mathrm{~h}$ after the second GnRH injection with a sexed semen straw; SS-22 = timed AI $22 \mathrm{~h}$ after the second GnRH injection with a SS straw.

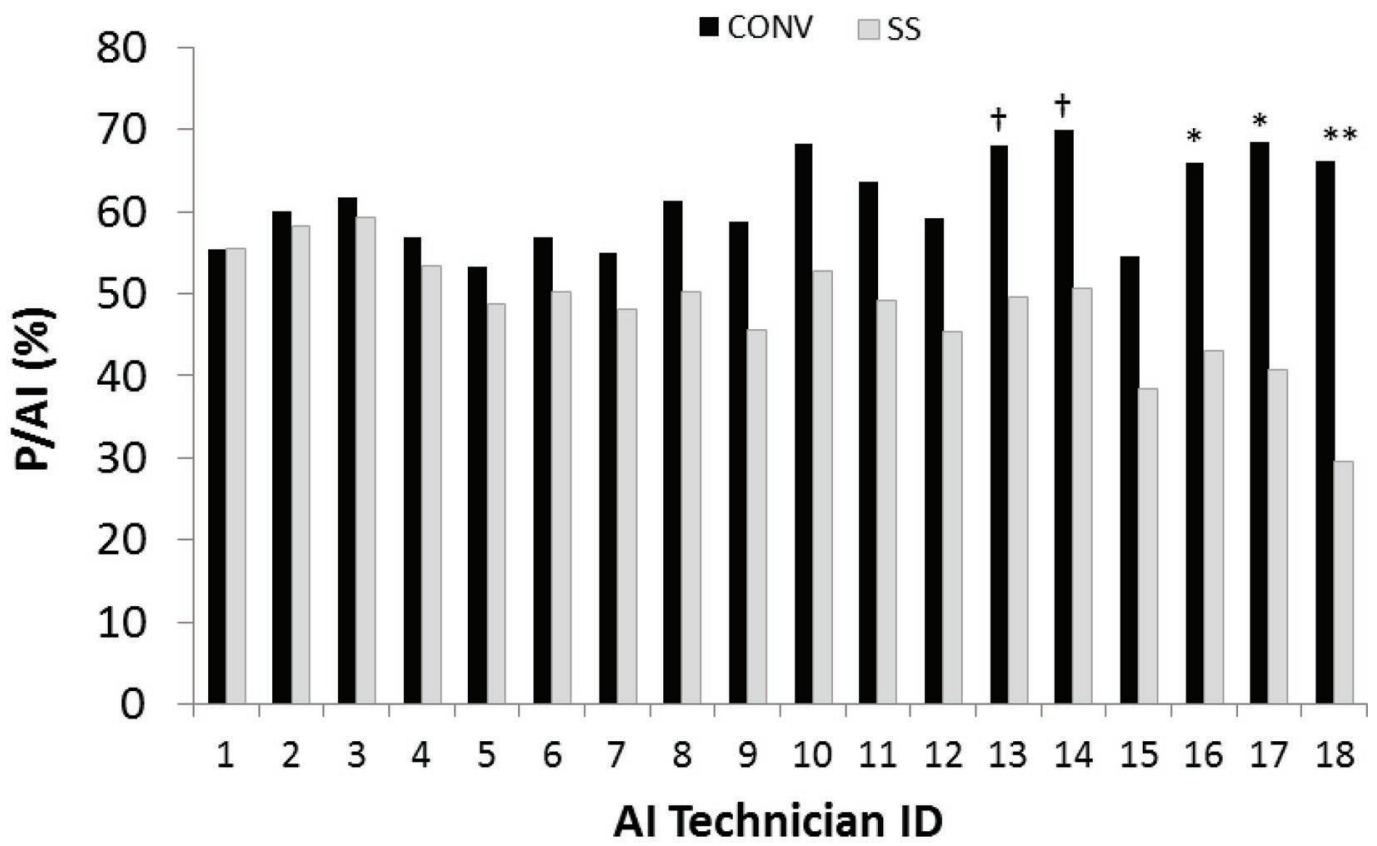

Figure 6. Mean pregnancy per AI (P/AI) for conventional (CONV) and sex-sorted (SS; SS-16 and SS-22 combined) for each technician, sorted based on $\mathrm{P} / \mathrm{AI}$ achieved with SS. Technicians 1 and 2 were assigned to 2 and 4 herds, respectively, and all other technicians were assigned to one herd. The type 3 test of fixed effects for treatment by herd interaction was not significant $(P=0.59)$. Partitioning the least squares means for the treatment by herd interaction using the SLICE statement indicated a significant effect for SS $(P=0.05)$ but not CONV $(P=0.99)$ $\dagger P<0.1{ }^{*} P<0.05 ;{ }^{*} P<0.01$. CONV = timed AI $16 \mathrm{~h}$ after the second GnRH injection with a conventional semen straw; SS-16 = timed AI $16 \mathrm{~h}$ after the second GnRH injection with a sexed semen straw; SS-22 = timed AI $22 \mathrm{~h}$ after the second GnRH injection with a SS straw. 
current study was not designed to test the effect of AI technician, but the results suggest that technician may have an important role to play in the success of SS. The multiple steps in the sorting procedure are damaging to sperm (Vishwanath and Moreno, 2018), and hence it is likely that straw handling procedures, thawing process (including temperature and duration), and duration from thawing to deposition of sperm in the uterus may be more critical for SS compared with CONV. A retrospective analysis of on-farm records in an Australian study (9,870 inseminations on 4,456 heifers) reported that AI technician had a significant effect on $\mathrm{P} / \mathrm{AI}$, and the authors suggested that the skill and experience of the AI technician may be more important for SS than for CONV (Healy et al., 2013).

In conclusion, no significant difference in P/AI was observed when cows were inseminated with SS at 16 or $22 \mathrm{~h}$ after $\mathrm{GnRH}$, suggesting that 16 to $22 \mathrm{~h}$ after $\mathrm{GnRH}$ likely encompasses the optimal window for timing of AI with SS. Overall, the relative P/AI was $83.5 \%$, but considerable variation between herds and between AI technicians was observed. It is noteworthy that some herds were able to achieve exceptional results with SS, whereas other herds had relatively poor performance, the reasons for which are currently unknown and warrant further investigation.

\section{ACKNOWLEDGMENTS}

We thank the following organizations for their participation in the study: the National Cattle Breeding Centre (Naas, Ireland), Dovea Genetics (Thurles, Ireland), Munster Bovine (Mallow, Ireland), Progressive Genetics (Enfield, Ireland), Cogent Breeding Ltd. (Chester, UK), Sexing Technologies (Navasota, TX), and Ceva Sante Animale (Libourne, France). We acknowledge the participation of the farmers, AI technicians, and veterinarians, and assistance from Walsh Scholar students at Teagasc Moorepark. We are grateful for the funding provided by the Irish Dairy Levy Trust (Dublin, Ireland) and the Irish Department of Agriculture, Food and the Marine (Dublin, Ireland) through Research Stimulus Fund project 15S732. The authors have not stated any conflicts of interest.

\section{REFERENCES}

Arruda, R. P., E. C. Celeghini, M. A. Alonso, H. F. Carvalho, K. M. Lemes, D. F. Silva, S. A. Rodriguez, and F. J. Affonso. 2012. Aspects related to the technique and the utilization of sexed semen in vivo and in vitro. Anim. Reprod. 9:345-353.

Bo, G. A., E. E. Huguenine, J. J. de la Mata, R. L. R. de Carneiro, and A. Menchaca. 2019. Pregnancy rates in suckled beef cows synchronized with a shortened progesterone/oestradiol-based protocol (J-synch) and inseminated with conventional or sexed-sorted semen. Reprod. Fertil. Dev. 31:129-129. https://doi.org/10.1071/ RDv31n1Ab7.

Bombardelli, G. D., H. F. Soares, and R. C. Chebel. 2016. Time of insemination relative to reaching activity threshold is associated with pregnancy risk when using sex-sorted semen for lactating Jersey cows. Theriogenology 85:533-539. https://doi.org/10.1016/ j.theriogenology.2015.09.042.

Burke, C., M. Blackwell, and S. Little. 2007. The InCalf book for New Zealand dairy farmers. Published by DairyNZ, Hamilton, New Zealand.

Butler, S. T. 2014. Nutritional management to optimize fertility of dairy cows in pasture-based systems. Animal 8(Suppl. 1):15-26. https://doi.org/10.1017/S1751731114000834.

Butler, S. T., I. A. Hutchinson, A. R. Cromie, and L. Shalloo. 2014 Applications and cost benefits of sexed semen in pasture-based dairy production systems. Animal 8(Suppl. 1):165-172. https:// doi.org/10.1017/S1751731114000664.

Chebel, R. C., and T. Cunha. 2020. Optimization of timing of insemination of dairy heifers inseminated with sex-sorted semen. J. Dairy Sci. 103:5591-5603. https://doi.org/10.3168/jds.2019-17870.

Dillon, P., S. Crosse, G. Stakelum, and F. Flynn. 1995. The effect of calving date and stocking rate on the performance of springcalving dairy cows. Grass Forage Sci. 50:286-299. https://doi.org/ 10.1111/j.1365-2494.1995.tb02324.x.

Frijters, A. C. J., E. Mullaart, R. M. G. Roelofs, R. P. Van Hoorne, J. F. Moreno, O. Moreno, and J. S. Merton. 2009. What affects fertility of sexed bull semen more, low sperm dosage or the sorting process? Theriogenology 71:64-67. https://doi.org/10.1016/j .theriogenology.2008.09.025.

Garner, D. L., K. M. Evans, and G. E. Seidel. 2013. Sex-sorting sperm using flow cytometry/cell sorting. Pages 279-295 in Spermatogenesis. Methods in Molecular Biology (Methods and Protocols), vol. 927. D. Carrell and K. Aston, ed. Humana Press, Totowa, NJ. https://doi.org/10.1007/978-1-62703-038-0_26.

Hall, J. B., R. K. Kasimanickam, J. B. Glaze Jr., and M. C. RobertsLew. 2017. Impact of delayed insemination on pregnancy rates to gender selected semen in a fixed-time AI system. Theriogenology 102:154-161. https://doi.org/10.1016/j.theriogenology.2017.07 .014 .

Healy, A. A., J. K. House, and P. C. Thomson. 2013. Artificial insemination field data on the use of sexed and conventional semen in nulliparous Holstein heifers. J. Dairy Sci. 96:1905-1914. https:// doi.org/10.3168/jds.2012-5465.

Herlihy, M. M., D. P. Berry, M. A. Crowe, M. G. Diskin, and S. T. Butler. 2011. Evaluation of protocols to synchronize estrus and ovulation in seasonal calving pasture-based dairy production systems. J. Dairy Sci. 94:4488-4501. https://doi.org/10.3168/jds .2010-4126.

Herlihy, M. M., M. A. Crowe, M. G. Diskin, and S. T. Butler. 2012. Effects of synchronization treatments on ovarian follicular dynamics, corpus luteum growth, and circulating steroid hormone concentrations in lactating dairy cows. J. Dairy Sci. 95:743-754. https://doi .org/10.3168/jds.2011-4779.

Holden, S. A., and S. T. Butler. 2018. Applications and benefits of sexed semen in dairy and beef herds. Animal 12(s1):s97-s103. https://doi.org/10.1017/S1751731118000721.

Holden, S. A., B. Fernandez-Fuertes, C. Murphy, H. Whelan, A. O'Gorman, L. Brennan, S. Butler, P. Lonergan, and S. Fair. 2017. Relationship between in vitro sperm functional assessments, seminal plasma composition, and field fertility after AI with either non-sorted or sex-sorted bull semen. Theriogenology 87:221-228. https://doi.org/10.1016/j.theriogenology.2016.08.024.

Hutchinson, I. A., L. Shalloo, and S. T. Butler. 2013a. Expanding the dairy herd in pasture-based systems: The role for sexed semen use on virgin heifers. J. Dairy Sci. 96:1312-1322. https://doi.org/10 $.3168 /$ jds.2012-6126.

Hutchinson, I. A., L. Shalloo, and S. T. Butler. 2013b. Expanding the dairy herd in pasture-based systems: The role of sexed semen use in virgin heifers and lactating cows. J. Dairy Sci. 96:6742-6752. https://doi.org/10.3168/jds.2012-6476. 
Johnson, L. A. 1995. Sex preselection by flow cytometric separation of $\mathrm{X}$ and $\mathrm{Y}$ chromosome-bearing sperm based on DNA difference: a review. Reprod. Fertil. Dev. 7:893-903. https://doi.org/10.1071/ RD9950893.

Karakaya, E., G. Yilmazbas-Mecitoglu, A. Keskin, A. Alkan, U. Tasdemir, J. E. P. Santos, and A. Gumen. 2014. Fertility in dairy cows after artificial insemination using sex-sorted sperm or conventional semen. Reprod. Domest. Anim. 49:333-337. https://doi.org/10 $.1111 /$ rda. 12280 .

Lauber, M.R., B. McMullen, J.J. Parrish, and P.M. Fricke. 2020. Effect of timing of AI using sexed semen relative to induction of ovulation after a Double-Ovsynch protocol on pregnancy outcomes and fetal sex in lactating primiparous Holstein cows. J. Dairy Sci. 103(Suppl. 1):93.

Maicas, C., S. A. Holden, E. Drake, A. R. Cromie, P. Lonergan, and S. T. Butler. 2020. Fertility of frozen sex-sorted sperm at $4 \times 10^{6}$ sperm per dose in lactating dairy cows in seasonal-calving pasturebased herds. J. Dairy Sci. 103:929-939. https://doi.org/10.3168/ jds.2019-17131.

Maicas, C., I. A. Hutchinson, J. Kenneally, J. Grant, A. R. Cromie, P. Lonergan, and S. T. Butler. 2019. Fertility of fresh and frozen sex-sorted semen in dairy cows and heifers in seasonal-calving pasture-based herds. J. Dairy Sci. 102:10530-10542. https://doi .org/10.3168/jds.2019-16740.

Maxwell, W. M. C., G. Evans, F. K. Hollinshead, R. Bathgate, S. P. De Graaf, B. M. Eriksson, L. Gillan, K. M. Morton, and J. K. O'Brien. 2004. Integration of sperm sexing technology into the ART toolbox. Anim. Reprod. Sci. 82-83:79-95. https://doi.org/10 .1016/j.anireprosci.2004.04.013.

Maxwell, W. M. C., and L. A. Johnson. 1997. Chlortetracycline analysis of boar spermatozoa after incubation, flow cytometric sorting, cooling, or cryopreservation. Mol. Reprod. Dev. 46:408-418. https://doi.org/10.1002/(SICI)1098-2795(199703)46:3<408::AIDMRD21>3.0.CO:2-T.

Maxwell, W. M. C., C. R. Long, L. A. Johnson, J. R. Dobrinsky, and G. R. Welch. 1998. The relationship between membrane status and fertility of boar spermatozoa after flow cytometric sorting in the presence or absence of seminal plasma. Reprod. Fertil. Dev. 10:433-440. https://doi.org/10.1071/RD98102.

Mee, J. F., F. Buckley, D. Ryan, and P. Dillon. 2009. Pre-breeding ovaro-uterine ultrasonography and its relationship with first service pregnancy rate in seasonal-calving dairy herds. Reprod. Domest. Anim. 44:331-337. https://doi.org/10.1111/j.1439-0531 .2008.01079.x

Randi, F., J. M. Sánchez, M. M. Herlihy, A. Valenza, D. A. Kenny, S. T. Butler, and P. Lonergan. 2018. Effect of equine chorionic gonadotropin treatment during a progesterone-based timed artificial insemination program on reproductive performance in seasonalcalving lactating dairy cows. J. Dairy Sci. 101:10526-10535. https: //doi.org/10.3168/jds.2018-14495.

Sá Filho, M. F., M. F. Mendanha, R. V. Sala, F. J. Carvalho, L. H. C. Guimarães, and P. S. Baruselli. 2013. Use of sex-sorted sperm in lactating dairy cows upon estrus detection or following timed artificial insemination. Anim. Reprod. Sci. 143:19-23. https://doi .org/10.1016/j.anireprosci.2013.10.014.

Sales, J. N. S., K. A. L. Neves, A. H. Souza, G. A. Crepaldi, R. V. Sala, M. Fosado, E. P. Campos Filho, M. De Faria, M. F. Sá Filho, and P. S. Baruselli. 2011. Timing of insemination and fertility in dairy and beef cattle receiving timed artificial insemination using sex-sorted sperm. Theriogenology 76:427-435. https://doi.org/10 .1016/j.theriogenology.2011.02.019.

Schenk, J. L., D. G. Cran, R. W. Everett, and G. E. Seidel Jr.. 2009. Pregnancy rates in heifers and cows with cryopreserved sexed sperm: Effects of sperm numbers per inseminate, sorting pressure and sperm storage before sorting. Theriogenology 71:717-728. https://doi.org/10.1016/j.theriogenology.2008.08.016.

Seidel, G. E. Jr. 2003. Economics of selecting for sex: The most important genetic trait. Theriogenology 59:585-598. https://doi.org/10 .1016/S0093-691X(02)01242-6.

Shalloo, L., A. Cromie, and N. McHugh. 2014. Effect of fertility on the economics of pasture-based dairy systems. Animal 8(Suppl. 1):222-231. https://doi.org/10.1017/S1751731114000615.

Shalloo, L., P. Dillon, M. Rath, and M. Wallace. 2004. Description and validation of the Moorepark dairy system model. J. Dairy Sci. 87:1945-1959. https://doi.org/10.3168/jds.S0022-0302(04)73353 -6 .

Suh, T. K., J. L. Schenk, and G. E. Seidel Jr.. 2005. High pressure flow cytometric sorting damages sperm. Theriogenology 64:1035-1048. https://doi.org/10.1016/j.theriogenology.2005.02.002.

Thomas, J. M., S. L. Lock, S. E. Poock, M. R. Ellersieck, M. F. Smith, and D. J. Patterson. 2014. Delayed insemination of nonestrous cows improves pregnancy rates when using sex-sorted semen in timed artificial insemination of suckled beef cows. J. Anim. Sci. 92:1747-1752. https://doi.org/10.2527/jas.2013-7131.

Thomas, J. M., J. W. C. Locke, R. C. Bonacker, E. R. Knickmeyer, D. J. Wilson, R. Vishwanath, A. M. Arnett, M. F. Smith, and D. J. Patterson. 2019. Evaluation of SexedULTRA 4M sex-sorted semen in timed artificial insemination programs for mature beef cows. Theriogenology 123:100-107. https://doi.org/10.1016/j .theriogenology.2018.09.039.

Vishwanath, R., and J. F. Moreno. 2018. Semen sexing-current state of the art with emphasis on bovine species. Animal 12(s1):s85-s96.

Weigel, K. A. 2004. Exploring the role of sexed semen in dairy production systems. J. Dairy Sci. 87:E120-E130. https://doi.org/10 .3168/jds.S0022-0302(04)70067-3.

Xu, Z. Z., G. Hamil, R. J. Spelman, M. Stiaque, and R. Vishwanath. 2018. Reproductive performance of sex-sorted semen in lactating dairy cows on pasture. Page 106 in Proc. 2018 SSR 51st Annual Meeting Abstracts, New Orleans, LA. Society for the Study of Reproduction, Reston, VA.

\section{ORCIDS}

S. A. Holden (ํ) https://orcid.org/0000-0002-3303-9580

R. C. Doyle $\odot$ https://orcid.org/0000-0002-8246-7039

S. G. Moore @ https://orcid.org/0000-0001-9896-8519

C. Maicas ๑ https://orcid.org/0000-0002-9315-1443

F. Randi (๑) https://orcid.org/0000-0001-6400-7429

P. Lonergan (ํ) https://orcid.org/0000-0001-5598-5044

S. T. Butler (1) https://orcid.org/0000-0003-1542-8344 